\title{
Industry and Academia Networks
}

Fernando Romero

Universidade do Minho, Portugal

\section{INTRODUCTION}

Universities have historically been a source of fundamental knowledge, and the premier source of technologies that have found innumerable applications (in the economy, in the military, in health care, etc.) that have shaped the trajectory, the direction and the nature of social and economic development. The contribution of universities towards the economic fabric of a region, nation or supranational entity is manifold, and is recognised as essential to the creation of wealth. It is because of that recognition that there has been a growing need to understand in what ways knowledge created at the universities is transferred and it impacts upon society at large. Knowledge can take many forms, and the resources devoted to knowledge creation can themselves be allocated to different levels and degrees of activities related to that endeavour. However, resources are scarce and resource allocation to knowledge must be essentially of a long-range perspective. The distribution of resources in terms of short-range and long-range investment in knowledge is inextricably linked to the phenomena of university-industry relations. Many initiatives fostering linkages between universities and industry, with a view to increase or facilitate rates of technology transfer, implemented innovation and economic development. However, the contexts in which these relations occur vary broadly and presently, because resources for investment in knowledge creation are scarce and differentiated there is a need for a comprehensive understanding of the variety of initiatives and relationships that exist, and the need for a deeper conceptualization of the forms, configurations, roles and expectations that shape and define existing relationships.

\section{TRENDS IN UNIVERSITY-INDUSTRY RELATIONS}

Relations between university and industry are not new and they have changed with the evolution of the university itself, the evolution of industry and the policy initiatives and objectives surrounding the university institution. The origins of the modern research university, as we know it today, can be traced back to the second half of the nineteenth century, whereby the main values that described the institution were: 1 ) the production of knowledge for its own sake; 2) the preparation for professional careers; 3 ) a structure based on well-defined disciplines and 4) an articulate organisation and a legal status (Geuna, 1999). The university was already seen as a national institution and its mission was related to the development of the nation-state. Explicit orientation to the needs of the local or regional economy was stronger in the United States universities than in the European ones, where research "for its own sake" was the predominant approach. During the $20^{\text {th }}$ century, institutional diversification and expansion gave birth to a set of "higher education" institutions that had a diverse approach as it concerned relations with industry or local economic needs and/or emphasis on "pure" research. After the $2^{\text {nd }}$ world war, the role of science and technology in terms of its direct applicability to economic development was firmly established among the western nations, although a linear perspective of the innovation process persisted. Governments diverted huge resources to research and development (not only to universities but also to other public agents) in the belief that such an investment, through a "pipeline" mechanism, would be transfigured into new processes and products and ultimately in increased wealth. More recently, several factors have transformed the way the university approaches its relations with industry. The perception that the innovation process is not a linear one and that the activities of basic research and development have and need innumerable connections, the increasing complexity of science and technology and the associated uncertainty and risks in the development of new products and processes, and the proliferation of public and private actors that are engaged in research and development activities, has put new demands and pressures on the university system.

Increasing connections between academia and industry are visible in several indicators. Statistics on the percentage of the total expenditure on $\mathrm{R} \& \mathrm{D}$ performed 
by the Higher Education sector that is financed by the Business sector (OECD, 2003), including the EU15 countries plus Canada, Japan and USA, show a percentage of $2.2 \%$ in 1981 and a percentage of $5.5 \%$ in 2001 . There is a wide diversity between countries, and the percentages vary from $1 \%$ to $13 \%$. The USA is in the middle of the league. During the 1980 decade, there was a very rapid rate of increase (averaging $15 \%$ per year) and during the 1990s and 2001, the rising trend persisted but at a slower and declining rate (about $4.5 \%$ per year). The pattern of growth during the first period was probably related to the spread of policy initiatives that supported increasing university-industry relations, whereas the pattern of growth during the last period was tentatively related to natural constrains or opportunities that limit the usefulness and growth of UIR. The ensuing discussion will elaborate further on that aspect.

According to recent data (OECD, 2000) both the relative and the absolute number of publications coauthored by industry and university researchers are also increasing.

The number of scientific papers that is cited by patents is also increasing, showing the impact that academic research is having on industrial inventive activity. Technological innovation makes increasing use of academic research output but the intensity and the degree of connection seems subject to considerable variability across fields.

The number of firms that are created based on university research (spin-off firms) is also growing, and varies wildly across countries, both in absolute (number of spin-offs per year) and relative terms (number of spin-offs per research expenditure).

\section{UNIVERSITY-INDUSTRY RELATIONS AND SOCIAL NETWORK THEORIES}

The advantages of having relationships with a widevariety of actors in diverse institutional settings have long attracted the attention of scholars (Freeman, 2004). There are a few sociological concepts that help explain themechanisms of information diffusion and knowledge exchange within or across networks, one of which is the concept of strong and weak ties (Granovetter, 1973). A strong tie represents a person with whom there is a regular interaction, and a weak tie represents a person with whom there are sporadic or punctual contacts. The source of much of new information that a person receives comes from weak ties, while strong ties are important in terms of day-to-day social interaction and support. Weak ties are the source of new ideas or new perspectives at looking at old problems. Strong ties are relevant in the exchange of complex information and conducive to the exchange of detailed and thick information (Ahuja, 2000). Applying these concepts to UIR, we can consider that researchers in academia are in a day-by-day basis in contact with their peers, their colleagues, with whom they share and construct complex information, but based on common beliefs and common approaches to solve problems (strong ties). The same can be said of researchers in an industrial setting. Complex and detailed information concerning that setting is shared between colleagues and co-workers, but it is common that a unique problem-solving paradigmatic approach prevails among the group. If a relationship is formed between a member of this group and a member of the academic group (weak tie), there is a high probability that new and fresh insights into old problems may occur, because of the different intellectual trajectories, constructs and perspectives that each individual brings with them. New possible knowledge combinations, otherwise difficult to obtain if the individuals were kept apart, can result from that interaction, and this applies to both sides of the relation.

Another conceptual perspective is the distinction between networks as bridges and networks as structural holes (Burt, 1992). Elements of a network may connect differently and with different persons. If a person knows another person in a network but a third person only knows the second, there is a not-yet-realised potential of connection between this last person and the first one. This configuration was defined by Burt as a structural hole, meaning the connection potential between elements or groups of elements that are not connected. There are elements that are better positioned than other to bridge and broker these gaps in the structure of the network, either to their own advantage or based on mediation and arbitration (Obstfeld, 2005).

This discussion highlights the advantages of university-industry relations (UIR), in terms of opening new avenues of research for members of academia and industry. Researchers in industry and researchers in academia have very different perspectives, experiences, and sensibilities and, in this sense, the two communities have inherent knowledge production advantages by creating communication channels and patterns of cooperation. 


\section{UNIVERSITY-INDUSTRY RELATIONS AND ECONOMIC THEORIES OF INNOVATION}

The discussion concerning UIR is related to the quest for optimal allocation of resources for knowledge production between public (e.g., universities) and private institutions (e.g., firms). In terms of economic theory, the concern is to maximise the social returns of that investment distribution. The discussion is complicated by the fact that knowledge has a public good nature that affects the way private and public returns are appropriated. Public goods are characterised by non-rivalry and nonexcludability, meaning that is difficult, or impossible, to assure exclusive access to them, as well as to have exclusive fruition of them. The nature of knowledge is conducive to a division of labour between basic research and applied research. Basic research, whose outcome is generally codified, and whose appropriability is low should be performed by public institutions. The applied or goal-oriented research, which implies, in general, an emphasis on tacit (non-codifiable) knowledge, which is more easily appropriated by the producer of that knowledge, is performed by profit seeking institutions. Under this linear perspective, the motivation for private firms to enter into relationships with universities would be to get access to basic knowledge, since the incentive of firms to invest internally in basic research would be too low.

If a non linear perspective of the process of knowledge creation and exploitation is adopted, other economic motivations may surge for firms to enter into relations with a university. There are explicit links and feedback loops between basic research and applied or goal oriented research (Rosenberg \& Nelson, 1994). As such, firms need, or are obliged by the very nature of the process of technological development, to engage in basic research activities in order to fully exploit technological opportunities. Firms have to build a minimum of internal capacities in order to be able to absorb and integrate profitably in their own product or service portfolio knowledge generated externally (Cohen \& Levinthal, 1990).

Firms contribute to scientific advancement when generating innovative solutions to technical bottlenecks faced in their design or production phases (Kline \& Rosenberg, 1986), and through the development of new scientific instruments (Shinn, 2005). The division of labour between public and private entities and the reasons for firms and universities to interact are thus more complex than a simple linear perspective would lead us to believe.

\section{FIRM'S KNOWLEDGE SEARCH PROCESS AND ORGANISATIONAL IMPLICATIONS}

The network mode of organization brought challenges to the traditional concept of an organization, and effectively blurred the boundaries of the organization we call firm (Colombo, 1998). Its raison d'étre may be explained in terms of transactions costs (Coase, 1937). The market, which is a coordination instrument based on the price mechanism, and which mediates the transactions and the interactions between economic agents, does not respond adequately or cost-effectively in certain situations. It may include situations where the price mechanism becomes costly to use or situations where a certain degree of uncertainty inherent in a market transaction exceeds a certain limit, and it becomes less costly if the transaction is made internally. Thus, the boundary of the firm is in itself a variable on which an economic assessment has to be made. Transactions that are straightforward, non-repetitive and do not require investment specific to that transaction, are made or are more likely to occur on markets; but transactions whose outcome is uncertain or difficult to anticipate with precision, recur frequently or require substantial amounts of transaction-specific investment, are more likely to occur within the boundaries of the firm (Williamson, 1981). The production and exploitation of new knowledge, is by nature, an activity with a high degree of uncertainty. Investment in knowledge generation functions by a firm will affect its boundaries, depending on the characteristics of the knowledge that is being produced. As a general rule, one may say that knowledge that is on the public domain, is codified (for instance in books, blueprints or software), and is easily accessible, will be preferentially contracted out in the market. Knowledge that is only mastered by a limited, or defined, group of people, and that it requires a considerable tacit dimension (i.e., knowledge that it is not amenable to codification, and is embedded in practice and know-how), will be preferentially internalised by the firm. However, in a rapidly changing scientific and technological landscape, a firm may not have the resources to pursue all desirable avenues of research, 
and is at that point that UIR may introduce a valuable and necessary strategic approach to the management of the research function.

\section{FROM COLLABORATION IN SCIENTIFIC NETWORKS TO UNIVERSITY-INDUSTRY RELATIONS}

Informal networks between individual researchers and between laboratories situated in different institutional settings or in different countries are as old as organized science and are inherent to the existence of "communities" of scientists and engineers belonging to the same discipline or working in the same or related field. Collaboration between scientists has been rising (Moed, Glänzel, \& Schmoch, 2004) and this trend may be related to changes in the organization of scientific work. There is a multiplication of team work after the mid-twentieth century, related to public investment in large research projects. Team work has evolved to giant research projects, or "big science" as it is often called, of which the most common examples are related to high energy physics and aerospace research. Large projects in the field of molecular biology and biomedical research (e.g., the Genome project) have also introduced a truly networked and distributed form of organisation. Teamwork seems to represent a new paradigm in the organisation of scientific research, and marks a discontinuity with earlier research practices (Beaver, 2001).

The trend in scientific collaboration is not divorced from the trends in university-industry cooperation. The practice of team-work has spread out to include participants that are external to the university. A bibliometric study, spanning a period of two centuries, on the collaboration between scientists (Wagner-Dobler, 2001), seems to indicate that collaboration (measured by co-authorship) increases in scientific fields that become, with time, more applied (to industrial applications). Collaboration intensity is not due to funding or specialization (which are commonly advanced causes) but by the application potential of theoretical science. That conclusion is in accordance with other empirical results, showing that the intensity of university-industry relations is sector-specific, and is greater, for instance, in the biotechnology, ICT or aerospace fields (Faulkner \& Senker, 1994; Faulkner, \& Velho, 1998; NSF, 2001;
Senker), sectors in which there has been a huge increase in commercial applications.

University responsiveness to economic demand is also evident in a country-specific study (Meyer-Krahmer \& Schmoch, 1998), whereby the science-based sectors have, in this case, the lowest intensity of cooperation. This pattern is tentatively explained by the industrial structure of the country, which is highly specialized in fields which require fewer inputs from science (e.g., the mechanical sector or a more traditional chemical sector). Patterns of university-industry interaction, strongly reflecting country-specific industrial structure characteristics, are evident in other studies ( Sanchez \& Tejedor, 1995; Mansfield \& Lee, 1996; Leydesdorff, 2004).

The growth and spread of knowledge-intensive firms has also revived and accentuated the importance of UIR, and specifically, the role of research and development within the network knowledge relationships (Bania, Eberts, \& Fogarty, 1993; Swann \& Prevezer, 1996; Owen-Smith, Riccaboni, Pammolli, \& Powell, 2002; Wilkinson \& Young, 2002; Miotti \& Sachwald, 2003; Roijakkers \& Hagedoorn, 2006).

\section{MOTIVATIONS FOR UNIVERSITY-INDUSTRY COLLABORATION}

Aside from theoretically-based sociological or economic arguments that contextualise university-industry interactions, there are a number of other commonly advanced causes to explain the rise in UIR. They include the increase in multi-disciplinarity and complexity of scientific and technological knowledge and the prohibitive costs of some projects, which extend beyond the capacities or competencies of any given institution, laboratory or discipline. Advances in information and communication technologies are also referred to as an important cause for the rise in collaborative activities.

Below follows a classification of the motivations for entering an university-industry relation from the point of view of the firm (Bonaccorsi \& Piccaluga, 1994), which is corroborated in many other studies (Feller \& Roessner, 1995; Sanchez \& Tejedor, 1995; Feldman, Feller, Bercovitz, \& Burton, 2002; Leydesdorff, 2003):

Obtaining early access to scientific breakthroughs 
- Increasing the predictive and applied power of science; includes simulation, modelling, training

- Delegating selected development activities; includes risk sharing, cost saving

- Lack of resources; for example, getting access to laboratories and equipment

From the point of view of the university, the motivations for establishing UIR are not so explored in the literature, but seem to fall in the following categories ( Lee, 1996; Azagra-Caro,Archontakis, Gutiérrez-Garcia, \& Fernandéz-de-Lucio, 2006):

- Knowledge motivations; to access or to interact with knowledge developed externally, in firms or other institutions, and to engage in oriented research

- $\quad$ Political motivations; policies have been set up to encourage scientific collaboration, motivated by the belief that collaboration maximizes public investment in research funding

- $\quad$ Financial motivation; obtaining additional funds for research

A comment is due in the first point, because the widespread notion in the literature is still that UIR are unidirectional relations, where industry is seeking knowledge from university, and not bidirectional, as it seems to be more the case (Meyer-Krahmer \& Schmoch, 1998). That would explain why UIR are less intense in regions where industry is less developed (Sanchez $\&$ Tejedor, 1995), and why size of firm seems to be an important determinant of university-industry interaction (Fontana, Geuna, \& Matt, 2006). Large firms have generally built a stock of knowledge that is unique. Complementary between different research orientations seems to drive the exchange of knowledge in the common interests of both parts. This perspective is in line with sociological explanations.

\section{CURRENT TRENDS ON UNIVERSITY-INDUSTRY RELATIONS}

There are many forms of university-industry relations. It can take the form of a researcher from the university advising and contributing to the resolution of a technical problem in a firm; it can take the form of an organised cooperation like the London Technology Network (LTN), where several universities and companies network in order to facilitate access and transfer of knowledge; or it can be a very structured and purposeful institutional arrangement, like the Engineering Research Centres (ERCs), a U.S. government initiative, which involved active participation of firms and universities in pre-competitive research and development activities, and related educational activities. The mechanisms for UIR include both formal and informal. The informal mechanisms are much more common than the formal ones. The formal mechanisms (joint labs, spin-off firms and contract research) represent only the tip of an iceberg (see Figure 1). The more common formal mechanism is contract research. Licensing has gained increased acceptance. Most universities have implemented policies to exploit their intellectual property holdings, and have established technology transfer offices (Mowery \& Nelson, 1999). However, the majority of UIR are established trough informal contacts and channels (mobility of researchers, co-publications, conferences, exhibitions \& specialised media, informal contacts within professional networks, flow of graduates to industry).

Responses to a large survey on R\&D performing firms in the USA (Cohen, Nelson, \& Walsh, 2002) “...suggest that the contribution of public research to industrial R\&D is principally via research findings, and this contribution is far greater than that of prototypes [built cooperatively]..." (p.8). The authors also found that the preferred channels for the information flow

Figure 1. The iceberg of university-industry relations (OECD, 2000)

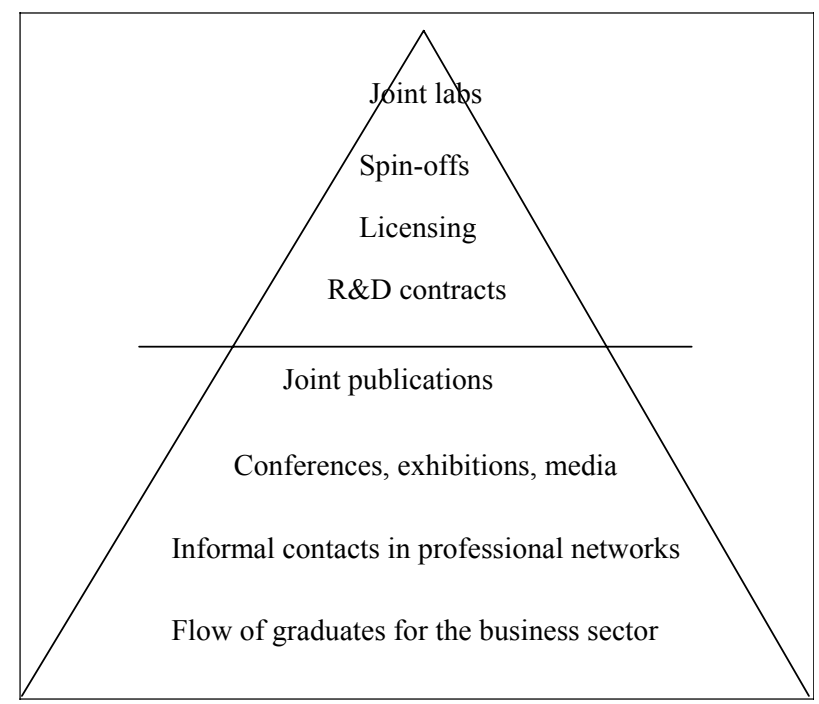


between academia and industry were related to those of "open science," namely publications, public meetings and conferences. Geographic proximity is an important determinant of UIR (Mansfield \& Lee, 1996), which is probably due to the fact that many, if not most, UIR are established on the basis of personal and close interactions (Feldman, Feller, Bercovitz, \& Burton, 2002).

\section{CURRENT DEBATES ON THE IMPLICATIONS OF UNIVERSITY-INDUSTRY RELATIONS}

Current debates focus on the implications of UIR on the division of knowledge production labour between public and private entities and the consequences in terms of availability of knowledge and future innovation-based economic development.

There are approaches that defend an anti-differentionist stance (Gibbons, 2000), arguing that the contemporary knowledge production process proceeds in a way that the distinction between the mission and roles of different actors are disappearing or fading away, predicting the collapse of the university and scientific disciplines and specialties. Other authors (Etzkowitz \& Leydesdorff, 1998), although not denying distinct roles for each institution, propose a deeper integration between three broad categories of actors (university, industry, government). Although acknowledging the different roles and missions of each broad category of actors, the authors defend that the character and culture of each actor is being mutually absorbed by the other(s), and all are loosing their distinctive features. Arguing for a more entrepreneurial university they propose that the normative structure of science should change from the notion of "communalism" to the notion of "capitalisation."

Other authors (Shinn, 2002) argue that the above mentioned perspectives lack a historical perspective on the relations between university and other actors, wrongly assuming that collaboration dynamics is a recent phenomena. The notion of "transversality" is proposed to describe and explain the behaviour of groups of technologists, active for at least two decades and responsible for the development of radically new devices and instrumentation, that operate at the interface between established institutions, "...both sustaining instituted differentiations and divisions of labour and violating them" (p.612). Collaboration has become gradually more important because there is a growing cognitive and organizational fragmentation (Shinn, 2005).

There are authors (Vavakova, 1998) arguing that there is a political drive behind the claims for a redesign of the mission of the university that creates an imbalance between the private and social returns of research activity. Excessive redesign of the university mission will lead to reduction of knowledge available as a public good and the manipulation of the public research agenda by private interests.

There are warnings (Geuna, 1998) against the perils of science policies that force universities, through financial cutbacks, towards a policy of fund seeking through increased contractual research with industry. Emphasising that there are various categories of universities there is a prediction of differential behaviour of universities in their relations with industry. There will be a polarisation of the university system, whereby “...only a restricted group of elite research intensive universities will go through the institutional adaptation to the changing environment, while managing to retain a few of the important features that historically have characterised the university. The majority of institutions currently identified as universities will be marginalised by the changes...pushed by government policy to satisfy the current needs of mass higher education and industrially oriented research..." (p. 267).

Research suggests that faculty that engage in contract research or in other interactions with industry, is not affected in terms of research productivity and the type of research that is performed (Gulbrandsen \& Smeby, 2005).

Some authors (Geuna \& Nesta, 2006) express doubts on the advantages of deepening the entrepreneurial university and the inevitable and accompanying privatisation of its generated knowledge. The argument is that most universities' technology transfer offices do not generate positive net incomes from licensing or from equity investments. Investing in start-up firms based upon (university) patents is a very uncertain and risky business, and the typical success rate is rather low.

Other authors defend that to increase the spin-off firms success rate, a proper institutional environment, that addresses typical university rigidities, should be created (Debackere, 2000).

Note should be taken that the bulk of research that is done at the university is basic research (Rosenberg \& Nelson, 1994), but that does not mean that it is not influenced by important technological problems or 
objectives. Furthermore, the bulk of research is done in the engineering or otherwise applied disciplines. Firms are much better at research on focused, shortterm problems, and do not invest much in basic research because the return on that investment is uncertain or of a long-range nature.

Concerns about the availability of public knowledge that can be jeopardised by the privatisation of university knowledge are raised (Nelson, 2001), and it is reaffirmed the contribution to economic development that universities have historically made (either in the past or recently), through their research activity and through mechanisms of open science. The cases of the biotechnology and ICT sector, which draw heavily on the competencies developed at universities, are recent examples. The university, by tending to increase the privatisation of its own knowledge output, and effectively starting or tending to use the same weapons of private entities, is entering a dangerous terrain that may eventually affect and overhaul its whole structure, rationale and support.

Future research is most likely to proceed along two lines: one that looks at the comparative efficiency of the several knowledge transfer mechanisms that the university institution has adopted, and the implications in terms of division of innovative labour and optimal allocation of knowledge resources. The other line of research, based on quantitative and qualitative techniques of network analysis, will look at network configuration and structure, and its implications in terms of knowledge production and application.

\section{CONCLUSION}

University-industry collaboration has risen in recent years. Network and cognitive advantages have been determinants of this trend, which has been politically encouraged. Causes seem to be related to changes in the scientific and technological landscape and the ensuing opportunities perceived by the market and the search for competencies that universities can provide in times of change. The university has historically been responsive to demands for opportunities, albeit in peculiar ways, and has contributed, directly and indirectly, to economic development and wealth creation, adopting several mechanisms that promote or facilitate knowledge transfer or exchange. An excessive emphasis on the mission of the university to satisfy immediate societal knowledge needs may compromises other missions, notably the fundamental knowledge production function that underpins future innovation and economic development. A balance between the functions of the university must be reached.

\section{REFERENCES}

Ahuja, G. (2000). Collaboration networks, structural holes and innovation: A longitudinal study. Administrative Science Quarterly, 45(3), 425-455.

Azagra-Caro, J., Archontakis, F., Gutiérrez-Garcia, A., \& Fernandéz-de-Lucio, I. (2006). Faculty support for the objectives of university-industry relations versus degree ofR\&D cooperation: Theimportance of Regional Absorptive Capacity. Research Policy, 35(1), 37-55.

Bania, N., Eberts, R., \& Fogarty, M. (1993). Universities and the startup of new companies: Can we generalize from Route 128 and Silicon Valey? The Review of Economics and Statistics, 75(4), 761-766.

Beaver,D.(2001). Reflections on scientific collaboration (and its study): Past, present, and future. Scientometrics, 52(3), 365-377.

Bonaccorsi, A., \& Piccaluga, A. (1994). A theoretical framework for the evaluation of university-industry relationships. $R \& D$ Management, 24(3), 229-247.

Burt, R. (1992). Structural holes. Cambridge, MA: Harvard University Press.

Coase, R. (1937). The nature of the firm. Economica, 4(16), 386-405.

Cohen, W., \& Levinthal, D. (1990). Absorptive capacity: A new perspective on learning and innovation. Administrative Science Quarterly, 35(1), 128-152.

Cohen, W., Nelson, R., \& Walsh, J. (2002). Links and impacts: The influence of public research on industrial R\&D. Management Science, 48(1), 1-23.

Colombo, M. (1998). The changing boundaries of the firm: Explaining evolving inter-firm relations London: Routledge.

Debackere, K. (2000). Managing academic R\&D as a business at K. U. Leuven: Context, structure and process. $R \& D$ Management, 30(4), 323-328. 
Etzkowitz, H., \& Leydesdorff, L. (1998). The endless transition: A "triple helix" of university-industry-government relations. Minerva, 36(3), 203-208.

Faulkner, W., \& Senker, J. (1994). Making sense of diversity: Public-private sector research linkage in three technologies. Research Policy, 23(6), 673-695.

Feldman, M., Feller, I., Bercovitz, J., \& Burton, R. (2002). Equity and the technology transfer strategies of American research universities. Management Science, 48(1), 105-121.

Feller, I., \& Roessner, D. (1995). What does industry expect from university partnerships?. Issues in Science \& Technology, 2(1).

Fontana, R., Geuna, A., \& Matt, M. (2006). Factors affecting university-industry R\&D projects: The importance of searching, screening and signalling. Research Policy, 35(2), 309-323.

Freeman, L. (2004). The development of social network analysis: A study in the sociology of science. Vancouver: Empirical Press.

Geuna,A. (1998). The internationalisation of European universities: Areturn to medieval roots. Minerva, 36(3), 253-270.

Geuna,A.(1999). The economics of knowledge production: Funding and the structure of university research. Cheltenham: Edward Elgar.

Geuna,A., \& Nesta, L. (2006). University patenting and its effects on academic research: The emerging European evidence. Research Policy, 35(6), 790-807.

Gibbons, M. (2000). Changing patterns of university - Industry relations. Minerva, 38(3), 352-361.

Granovetter, M. (1973). The strength of weak ties. American Journal of Sociology, 78, 1360-1380.

Gulbrandsen, M., \& Smeby, J. (2005). Industry funding and university professors' research performance. Research Policy, 34(6), 932-950.

Kline, S., \& Rosenberg, N. (1986). An overview of innovation. In R. Landau \& N. Rosenberg (Eds.), The positive sum strategy: Harnessing technology for economic growth. Washington, DC: The National Academy Press.
Lee, Y. (1996). 'Technology transfer' and the research university: A search for the boundaries of universityindustry collaboration. Research Policy, 25(6), 843 863.

Leydesdorff, L. (2003). A methodological perspective on the evaluation of the promotion of university-industry-government relations. Small Business Economics, 20(2), 201-204.

Leydesdorff, L. (2004). The university-industry knowledge relationship: Analyzing patents and the science base of technologies. Journal of the American Society for Information Science and Technology, 55(11), 9911001 .

Mansfield, E., \& Lee, J.-Y. (1996). The modern university: Contributor to industrial innovation and recipient of industrial R\&D support. Research Policy, 25(7), 1047-1058.

Meyer-Krahmer, F., \& Schmoch, U. (1998). Sciencebased technologies: University-industry interaction in four fields. Research Policy, 27(8), 835-851.

Miotti, L., \& Sachwald, F. (2003). Co-operative R\&D: Why and with whom? An integrated framework of analysis. Research Policy, 32(8), 1481-1499.

Moed, H., Glänzel, W., \& Schmoch, U. (2004). Handbook of quantitative science and technology research: The use of publication and patent statistics in studies on S\&T systems. Dordrecht: Kluwer Academic Publishers.

Mowery, D., \& Nelson, R. (1999). Sources of industrial leadership. New York, NY: Cambridge University Press.

Nelson, R. (2001). Observations on the Post-Bayh-Dole rise of patenting at American universities. The Journal of Technology Transfer, 26(1-2), 13-19.

NSF. (2001). Survey of industrial research and development: Arlington, VA: National Science Foundation.

Obstfeld, D. (2005). Social networks, the Tertius Jungens orientation, and involvement in innovation. Administrative Science Quarterly, 50(1), 100-130.

OECD. (2000). OECD science, technologyand industry outlook 2000. Paris: OECD.

OECD. (2003). Research and development statistics. Paris: OECD.

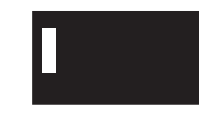


Owen-Smith, J., Riccaboni, M., Pammolli, F., \& Powell, W. (2002). A comparison of U.S. and European university-industry relations in the life sciences. Management Science, 48(1), 24-43.

Roijakkers, N., \& Hagedoorn, J. (2006). Inter-firm R\&D partnering in pharmaceutical biotechnology since 1975: Trends, patterns, and networks. Research Policy, 35(3), 431-446.

Rosenberg, N., \& Nelson, R. (1994). American universities and technical advance in industry. Research Policy, 23(3), 323-348.

Sanchez, A., \& Tejedor, A. (1995). University-industry relationships in peripheral regions: The case of Aragon in Spain. Technovation, 15(10), 613-625.

Senker, J., Faulkner, W., \& Velho, L. (1998). Science and technology knowledge flows between industrial and academic research: A comparative study. In H. Etzkowitz \& A. Stevens (Eds.), Capitalizing knowledge: New intersections of industry and academia (pp. 111-132). Albany, NY: State University of New York Press.

Shinn, T. (2002). The triple-helix and the new production of knowledge: Prepackaged thinking on science and technology. Social Studies of Science, 32(4), 599614.

Shinn, T. (2005). New sources of radical innovation: Research-technologies, transversality and distributed learning in a post-industrial order. Social Science Information, 44(4), 731-764.

Swann, P., \& Prevezer, M. (1996). A comparison of the dynamics of industrial clustering in computing and biotechnology. Research Policy, 25(7), 1139 -1157.

Vavakova, B. (1998). The new social contract between governments, universities and society: Has the old one failed? Minerva, 36(3), 209-228.

Wagner-Dobler, R. (2001). Continuity and discontinuity of collaboration behaviour since 1800- from a bibliometric point of view. Scientometrics, 52(3), 503-517.

Wilkinson, I., \& Young, L. (2002). On cooperating: Firms, relations and networks. Journal of Business Research, 55(2), 123-132.

Williamson, O. (1981). The economics of organization: The transaction cost approach. American Journal of Sociology, 87(3), 548-577.

\section{KEY TERMS}

Appropriability: Knowledge generated by a firm can be contained within its premises or it can leak out to other firms. If it is easily codified in books, blueprints or other means, its transmissibility is high and it has low appropriability. If the knowledge is difficult to codify then it has a high appropriability.

Excludable Goods: A good is excludable if the owner can preclude others from using it.

Linear Model of Innovation: A theory that holds that innovation is a process of discovery which proceeds via a fixed and linear sequence of phases. In this view, innovation begins with new scientific research, progresses sequentially through stages of product development, production and marketing, and terminates with the successful sale of new products, processes and services.

Patent: A patent for an invention is the grant of a property right to the inventor, issued by a government office. What is granted is not the right to make, use, offer for sale, sell or import, but the right to exclude others from making, using, offering for sale, selling or importing the invention.

Rival Goods: A good is rival if its use by one person excludes it from being used by another.

Science-Based Sectors: Industrial sectors that have research intensity above a certain percentage. Research intensity is defined as the ratio between $R \& D$ expenses and total sales. This term was defined by the Organisation for Economic Co-operation and Development (OECD).

Spin-Off Firm: A firm that is created by faculty personnel to exploit a research result produced with the research institution's physical, human and financial resources. A firm may also be a spin-off firm from another firm. In this case, it is defined as a firm created by ex-employees of the mother firm to exploit a research result produced with the firm physical, human and financial resources. 